\title{
Microscopy as a Powerful Technique to Characterise Polymer Matrix Nanocomposites
}

\author{
M. Oliveira* and A.V. Machado* \\ *IPC, Institute for Polymers and Composites/I3N, University of Minho, Campus de Azurém, 4800- \\ 058 Guimarães, Portugal
}

Polymer nanocomposites are a recent class of materials that have drawn considerable attention in recent years, due to the significant improvements in several properties [1]. Even though a lot of research has been performed on the preparation of these materials, the homogeneous dispersion of nanoparticles in polymeric matrices, especially in non-polar, is still a difficult task [2]. Thus, frequently nanocomposites exhibited worst properties than conventional polymers that limit their effective application. One way to improve nanoparticles dispersion is by using an in situ sol-gel method, which is based on a reaction between a precursor, containing the inorganic particle, and a polymer followed by hydrolysis-condensation reaction [3]. Therefore, the present work aims to use microscopy techniques to investigate the dispersion of nanoparticles containing aluminium in PP and EVA matrices, prepared by a sol-gel process in the melt.

Polypropylene modified with maleic anhydride (PP-g-MA, Polybond 3200) supplied by Crompton and ethylene-vinyl acetate (EVA) with 12 wt.\% (EVA12, Escorene Ultra UL 00112) and 27 wt.\% (EVA27, Escorene Ultra UL 00328) of vinyl acetate supplied by Exxon Mobil, were used as organic matrices to prepared the nanocomposites. The precursor, aluminium isopropoxide ( $\left.\mathrm{Al}(\mathrm{Pr}-\mathrm{i}-\mathrm{O})_{3}\right)$, used as received in powder state, was supplied by Sigma Aldrich. Nanocomposites with the same composition were prepared by melt mixing in an internal mixer under constant processing conditions, as previously describe by Oliveira [3]. The hybrid nanocomposite $(\mathrm{HN})$ synthesized with PP-g-MA was called HN-Pr, with EVA12 was HNEVA12 and the one synthesized with EVA27 was HNEVA27. Samples characterized by SEM were fractured at low temperature and gold coated. Samples analysed by TEM were sectioned by cryo-ultramicrotomy using a diamond knife at $-60{ }^{\circ} \mathrm{C}$ and $-140{ }^{\circ} \mathrm{C}$ under liquid nitrogen for EVAs and PP-g-MA nanocomposites, respectively. X-ray microanalysis mapping was performed in $300 \mu \mathrm{m}^{2}$, in the same place where SEM analysis was made, with an energy dispersive X-ray Spectrometer (EDS) from Link eXL II from Oxford Instruments attached to the SEM.

SEM micrographs presented in Figure $1 \mathrm{a}, \mathrm{b}$ and $\mathrm{c}$ show that while HN-Pr has a homogeneous and rough surface, HNEVA12 and HNEVA27 have homogeneous and smoother surfaces. The presence of nanoparticles agglomerations can not be observed in the micrographs, which indicates a good dispersion and interaction between organic and inorganic components. Therefore, in order to investigate nanoparticles dispersion TEM analysis were performed and the results presented in Figure 2 evidence different degrees of nanoparticles dispersion in polymeric matrices and distinct sizes. The best dispersion was achieved in HN-Pr followed by HNEVA27. The average particle size is 200, 130 and $120 \mathrm{~nm}$ for HN-Pr, HNEVA12 and HNEVA27, respectively. The differences in particles dimension can be explained by the extension of the chemical reaction, which in agreement with other techniques, it was higher for EVA27. EDS analysis results presented in Figure 3 render 2.84, 5.07 and $3.49 \%$ of aluminium content in the analysed area of HN-Pr, HNEVA12 and HNEVA27, respectively.

In this study, it was observed that reaction extension has a great influence on size and dispersion of the generated nanoparticles. According to SEM and TEM results, the smallest nanoparticles were achieved in EVA27. Moreover, for the three nanocomposites prepared well dispersed nanoparticles were obtained. The EDS spectrum confirmed the presence of aluminium in nanocomposites structure. This work showed that microscopic technics are very powerful on the characterization of new polymer matrix nanocomposites. 


\section{References}

1. Turova N.Y. et al., In: The chemistry of metal alkoxide. eds. Kluwer Academic Publisher. Dordrecht, Netherlands, 149, 2002.

2. Wang K.H. et al., Polym., 42:9819 - 9826, 2001.

3. Oliveira M. et al., React. Funct. Polym., 72:703 - 712, 2012.

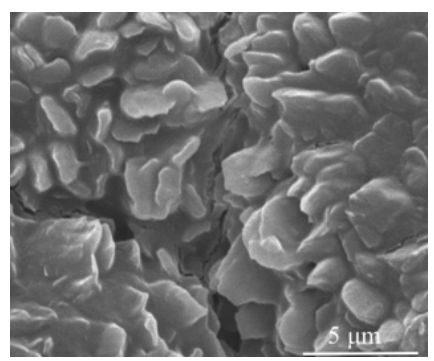

a)

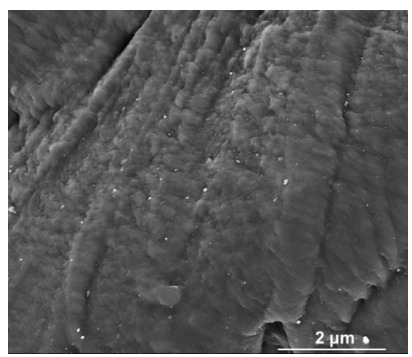

b)

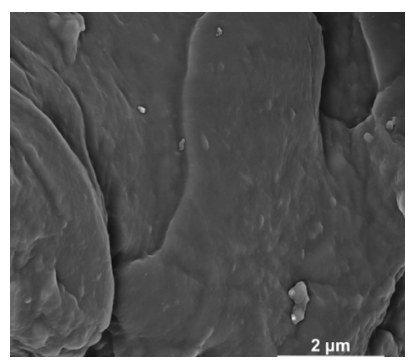

c)

Figure 1. SEM micrographs of a) HN-Pr, b) HNEVA12 and c) HNEVA27.

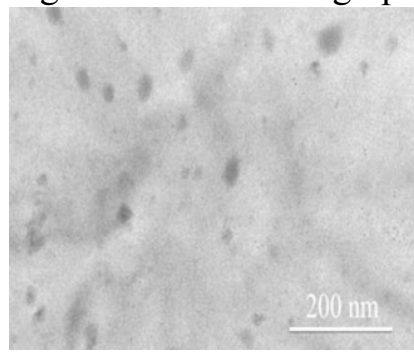

a)

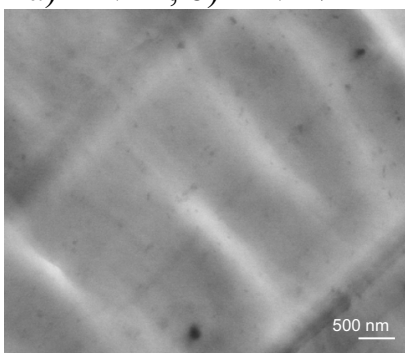

b)

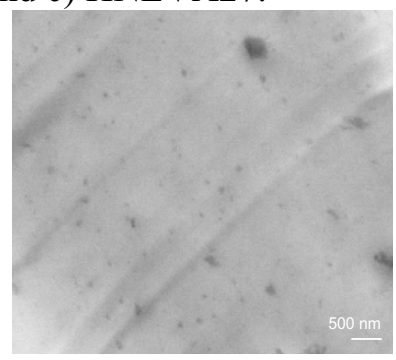

c)

Figure 2. TEM micrographs of a) HN-Pr, b) HNEVA12 and c) HNEVA27.

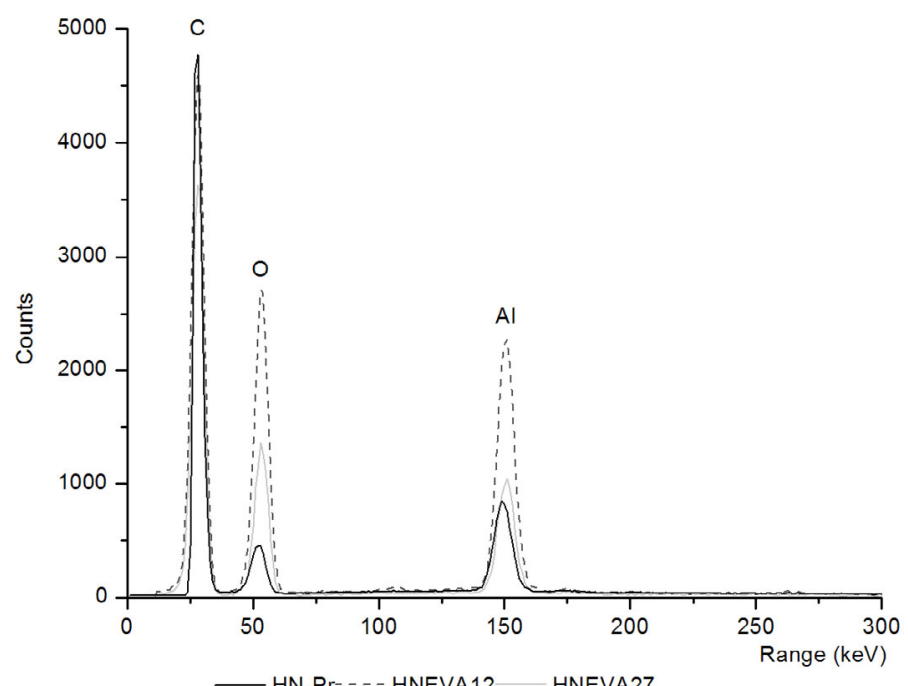

Figure 3. EDS spectra of the prepared nanocomposites.

The authors are grateful to the Portuguese Foundation of Science and Technology (FCT) Project SFRH / BD / 39085 / 2007 for the financial support. 